\title{
Impact of Age at Pediatric Stroke on Long-term Cognitive Outcome
}

Author(s):

Stephanie Abgottspon, MSc ${ }^{1,2,3}$; Qendresa Thaqi, $\mathrm{PhD}^{1,4}$; Leonie Steiner, MSc ${ }^{1,3}$; Nedelina Slavova, Dr. med. ${ }^{5,6}$; Sebastian Grunt, Dr. med. ${ }^{1}$; Maja Steinlin, Prof. Dr. med. ${ }^{1}$; Regula Everts, Prof. Dr. phil. ${ }^{1}$

Corresponding Author:

Regula Everts

regula.evertsbrekenfeld@insel.ch

This is an open access article distributed under the terms of the Creative Commons Attribution-NonCommercial-NoDerivatives License 4.0 (CC BY-NC-ND), which permits downloading and sharing the work provided it is properly cited. The work cannot be changed in any way or used commercially without permission from the journal.

Neurology® Published Ahead of Print articles have been peer reviewed and accepted for publication. This manuscript will be published in its final form after copyediting, page composition, and review of proofs. Errors that could affect the content may be corrected during these processes. 
Affiliation Information for All Authors: 1. Division of Neuropediatrics, Development and Rehabilitation, Department of Pediatrics, Inselspital, Bern University Hospital, University of Bern, Switzerland; 2. Department of Diabetes, Endocrinology, Nutritional Medicine and Metabolism, Inselspital, Bern University Hospital and University of Bern, Switzerland;3. Graduate School for Health Sciences, University of Bern, Bern, Switzerland; 4. University of Bern, Department of Psychology, 3012 Bern, Switzerland;5. Institute of Diagnostic and Interventional Neuroradiology, Inselspital, Bern University Hospital, 3012 Bern, Switzerland; 6. Pediatric Radiology, University Children's Hospital Basel and University of Basel, Switzerland

\section{Contributions:}

Stephanie Abgottspon: Drafting/revision of the manuscript for content, including medical writing for content; Analysis or interpretation of data

Qendresa Thaqi: Drafting/revision of the manuscript for content, including medical writing for content; Major role in the acquisition of data; Analysis or interpretation of data

Leonie Steiner: Drafting/revision of the manuscript for content, including medical writing for content Nedelina Slavova: Drafting/revision of the manuscript for content, including medical writing for content

Sebastian Grunt: Drafting/revision of the manuscript for content, including medical writing for content; Study concept or design

Maja Steinlin: Drafting/revision of the manuscript for content, including medical writing for content; Study concept or design

Regula Everts: Drafting/revision of the manuscript for content, including medical writing for content; Major role in the acquisition of data; Study concept or design; Analysis or interpretation of data

Number of characters in title: 68

Abstract Word count: 282

Word count of main text: 3336

References: 50

Figures: 2

Tables: 3

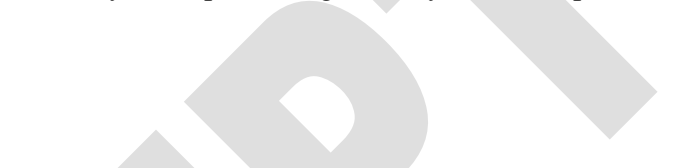

Supplemental: Manuscript_Revisions_tracked-changes Supplementary_material

Statistical Analysis performed by: Stephanie Abgottspon, Master of Science in Psychology, Division of Neuropediatrics, Development and Rehabilitation, Department of Pediatrics, Inselspital, Bern University Hospital, University of Bern, Switzerland Qendresa Thaqi, PhD in Psychology,Division of Neuropediatrics, Development and Rehabilitation, Department of Pediatrics, Inselspital, Bern University Hospital, University of Bern, Switzerland

Search Terms: [ 10 ] Childhood stroke, [ 204 ] Intelligence, [ 205 ] Neuropsychological assessment, [ 206 ] Executive function, [ 293 ] Pediatric stroke; see Cerebrovascular Disease/ Childhood stroke (S)

Acknowledgements: Our gratitude goes to the children, adolescents, and young adults who participated in the studies as well as their parents. Furthermore, we thank Salome Kornfeld, Juan Delgado-Rodriguez, Sandeep Kamal, Maria Regényi, and Jasmin Grolimund for their support in study coordination and data collection and Sarah Tanner for her help with the literature search. We also thank all the coworkers at the Swiss Neuropediatric Stroke Registry: Andrea Capone Mori (Aarau), Alexandre Datta (Basel), Joël Fluss (Geneva), Annette Hackenberg (Zürich), Elmar Keller (Chur), Oliver Maier (St. Gallen), Jean-Pierre Marcoz (Sion), Claudia Poloni (Lausanne), Gian Paolo Ramelli (Bellinzona), Regula Schmid (Winterthur), and Thomas Schmitt-Mechelke (Lucerne).

Study Funding: This study was supported by the Jacobs Foundation, the Stiftung Batzebär of the Children s University Hospital Bern (Switzerland), the Swiss National Science Foundation (SNF grant 32003B_146894/1), the Schweizerische Stiftung für das Cerebral Gelähmte Kind (Switzerland), the Vinetum foundation (Switzerland), and the Anna Müller Grocholski Foundation (Switzerland). 
Disclosures: The authors report no disclosures relevant to the manuscript.

\begin{abstract}
Objectives: To investigate the impact of age at pediatric arterial ischemic stroke on longterm cognitive outcome in order to identify patients particularly at risk for the development of cognitive long-term cognitive sequelae.

Methods: This cross-sectional study included patients in the chronic phase of stroke (> 2 years after stroke) previously diagnosed with neonatal or childhood arterial ischemic stroke and a control group. Participants with active epilepsy, severe learning difficulties, or behavioral problems hindering the cognitive assessment were excluded. Several cognitive domains, including intelligence, executive functions (working memory, inhibition, and cognitive flexibility), processing speed, memory, letter fluency, and visual-motor skills were assessed with neuropsychological tests. Cognitive long-term outcome was compared across patients after neonatal stroke (stroke between 0 and 28 days of life), early childhood stroke (stroke between 29 days and < 6 years) and late childhood stroke (stroke between $\geq 6$ and < 16 years).

Results: 52 patients after neonatal or childhood arterial ischemic stroke (median age: 15.3 years, IQR $=10.6-18.7$ ) and 49 healthy controls (median age: 13.6 years, IQR $=9.8-17.2$ ) met the inclusion criteria. Cognitive outcome was significantly worse in the pediatric stroke group compared to the control group. A non-linear effect of age at stroke (irrespective of lesion size and lesion location) was found for cognitive flexibility, processing speed, and verbal learning with early childhood stroke (29 days to < 6 years) showing significantly
\end{abstract}


worse cognitive outcome compared to neonatal or late childhood stroke $(p<.05$, FDRcorrected).

Conclusion: Age at stroke is an important factor for post-stroke recovery and modulates long-term cognitive outcome irrespective of lesion size and lesion location. Children after early childhood stroke are at particular risk for alterations of long-term cognitive functions. 


\section{Introduction}

Pediatric arterial ischemic stroke is a rare event but is accompanied by an increased risk for cognitive and neurological sequelae. ${ }^{1-3}$ Identification of factors associated with poor outcome has been the focus of research for several years; yet, knowledge about outcome prediction remains insufficient. $^{4-6}$

An inherent property of the developing brain is increased plasticity. ${ }^{7-9}$ Due to rapid synaptogenesis as well as increased myelination and reorganization processes of neuronal networks during this period, the developing brain is suggested to be more flexible with better recovery capacity after early brain insult. ${ }^{2,7,9}$ On the other hand, the developing brain is particular vulnerable for early brain insult, leading to disrupted brain development. ${ }^{7,9}$ In light of the two contradictory perspectives - plasticity versus vulnerability -, findings about the impact of age at pediatric stroke remain unclear with some studies showing that younger age at stroke is associated with worse $e^{6,10-13}$ or better cognitive outcome. ${ }^{14,15}$

Whereas several studies examined cognitive outcome in the acute phase of the stroke up until two years post-stroke, ${ }^{6,10,12}$ studies investigating the outcome of patients in the late chronic stage (> 2 years after stroke) are however limited. Focusing on patients in the late chronic stage is essential as deficits may emerge and increase over time $e^{5,11,16}$ and recovery processes can extend far beyond the first months post-stroke. ${ }^{17}$ Further, the developmental stage at the time of the brain insult can modulate cognitive outcome. ${ }^{18,19}$ Brain insults during a critical period of cognitive development likely entail poorer cognitive outcome compared to brain injuries occurring before or after the emergence of a cognitive function. ${ }^{19}$ Moreover, cognitive functions, in particular executive functions, are strongly associated with quality of life, ${ }^{20}$ scholastic achievement, ${ }^{21}$ and social competence, ${ }^{22}$ which highlights the importance to monitor post-stroke cognitive outcome.

In the present study, we aimed to examine long-term cognitive outcome following pediatric stroke in the chronic stage ( $>2$ years after stroke) and to investigate whether age at 
stroke impacts on cognition in order to identify patients at risk for poor cognitive outcome.

\section{Methods}

\section{Study Design and Study Population}

This cross-sectional study includes data from two research projects that were carried out at the Division of Neuropediatrics, Development, and Rehabilitation at the University Hospital in Berne, Switzerland (Hemispheric Reorganization study ${ }^{3}$ (HERO), 2014 - 2016 and Onset study (ONSET), 2019 - 2020). In both research projects, participants diagnosed with pediatric arterial ischemic stroke were recruited from the population-based Swiss Neuropediatric Stroke Registry (SNPSR). ${ }^{6,23}$ The control group was recruited through advertisement in the hospital intranet and flyers within the HERO study.

Inclusion criteria for the stroke group were a diagnosis of pediatric arterial ischemic stroke (neonatal or childhood stroke, confirmed by MRI or computed tomography) at least two years prior to study participation, age at stroke $\leq 16$ years and age at examination $\geq 6$ years. Exclusion criteria were active epilepsy (defined as seizures or treatment with antiseizure medication during the 12 months prior to study participation), additional neurological disorders not attributable to stroke, severe learning difficulties, or pronounced behavioral problems that would make assessments impossible. Patients with active epilepsy were excluded because transcranial magnetic stimulation (TMS) was performed as part of the HERO study. Inclusion criteria for the control group were age at examination $\geq 6$ years, no impairments influencing cognitive and neurological development. Exclusion criteria were the same as for the stroke sample.

\section{Standard Protocol Approvals, Registrations, and Patient Consents}


The study protocols of both research projects were approved by the Research Ethics Committee of Berne, Switzerland (HERO study: 212/13, ${ }^{3}$ ONSET study: 2019-00546). Depending on the age of the participants, written informed consent was obtained from the participant (if > 16 years of age) or parent / legal guardian (if < 16 years of age).

Examinations were performed at the University Hospital, Inselspital Bern or, in individual cases, home visits were performed. Both studies were conducted according to the Declaration of Helsinki.

\section{Clinical Data and Lesion Characteristics}

Clinical data, including sex, age at stroke, and stroke risk factors were obtained from medical records and the SNPSR database. Stroke risk factors were categorized according to Steinlin and Wehrli (2009). ${ }^{24}$ Lesion volume was estimated using the pediatric modification of the Alberta Stroke Program Early Computed Tomography Score (pedASPECTS) ${ }^{25-27}$, a score that was validated in a previous study in 71 individuals with neonatal or childhood arterial ischemic stroke. ${ }^{25}$ The procedure is described elsewhere. ${ }^{28,29}$ Maximum score of the pedASPECTS is 30, indicating uttermost severity. Scores were determined based on diffusion-weighted imaging sequences from the acute MRI, or - if not available - on morphological MR sequences of the first-available post-stroke brain MRI (T2-weighted imaging or fluid-attenuated inversion recovery (FLAIR) imaging). For seven patients, the acute MRI was not available and hence the pedASPECTS was determined using the firstavailable post-stroke MRI. PedASPECTS of patients with post-stroke MRI did not differ from pedASPECTS determined on the acute MRI $(p=.282)$. Information about lesion laterality (left, right, or bilateral) and lesion location (cortical, subcortical, or combined cortical and subcortical) were derived from the pedASPECTS. ${ }^{30}$ Neurological outcome at the time of the study assessment was assessed via the Pediatric Stroke Outcome Measure (PSOM). ${ }^{31}$ The PSOM consists of 5 subscales (right sensorimotor, left sensorimotor, 
language production, language comprehension, and cognitive/behavior) and yields a total score ranging from 0 (no deficits) to 10 (maximum deficits).

\section{Cognitive Assessments}

Several cognitive domains, such as nonverbal intelligence, executive functions, processing speed, memory, letter fluency, and visual-motor skills were evaluated during the neuropsychological assessment by an experienced neuropsychologist. A description of the cognitive tests and the outcomes is provided in Table 1. For all tests, age-corrected standard scores, index scores, or percentile ranks were used according to the test manual.

\section{Data Analysis}

To assess the impact of stroke on long-term cognitive outcome, the stroke sample was divided into three age-at-stroke groups: neonatal stroke (stroke between 0 and 28 days of life), early childhood stroke (stroke between 29 days and < 6 years), and late childhood stroke (stroke between $\geq 6$ and $<16$ years) such as described in a previous study. ${ }^{11}$ Additionally, we performed locally weighted regression and scatterplot smoothing (LOESS) to display possible associations between cognitive outcome and age at stroke and to verify the cutoff points of the age-at-stroke groups. ${ }^{32}$

Demographic and clinical data was presented for the control group and the three ageat-stroke groups. Continuous variables were reported in mean and standard deviation for normally distributed variables and in median and interquartile range for non-normally distributed yariables. Categorical variables were presented in frequencies and percentage. Descriptive and baseline variables in the three age-at-stroke groups were compared using analyses of variance (ANOVA) with Bonferroni's post hoc tests (or Kruskal-Wallis tests for non-parametric data) and Pearson's chi-square tests followed by post hoc pairwise comparisons. Group differences in cognitive performance between the total stroke sample and the control sample were computed using two-sided independent $t$-tests. To identify 
possible confounders, associations between lesion size, lesion location, lesion laterality, and cognitive outcome (within the total stroke group) were examined with two-sided Spearman correlations or ANOVAs, respectively. We did not investigate associations between stroke risk factors and cognitive outcome because of the limited number of patients in each stroke risk factor category.

To investigate the impact of age at stroke on long-term cognitive outcome, a series of one-way analyses of covariance (ANCOVAs) using the three age-at-stroke groups as independent variables and the respective cognitive domain as dependent variable (controlling for the effect of lesion size and lesion location) were conducted followed by Bonferroni's post hoc tests. Results of the ANCOVA analyses were reported as estimated marginal means with associated $95 \%$ confidence intervals. Cohen's d effect sizes were calculated for independent $t$-test and partial eta squared $\left(\eta_{\mathrm{p}}{ }^{2}\right)$ for ANCOVAS. ${ }^{33}$ Statistical significance was set at $p<.05$. We report alpha values adjusted according to the Benjamini-Hochberg procedure (false discovery rate, FDR) to correct for multiple testing. ${ }^{34}$ All statistical analyses were performed with the Statistical Package for Social Sciences (SPSS), version 25. Data visualization was generated using the R package ggplot $2 .^{35}$

\section{Data Availability}

All anonymized data is available on request from any qualified investigator. 


\section{Results}

\section{Baseline Characteristics}

Fifty-four participants diagnosed with pediatric stroke and 50 healthy controls were identified from the HERO or ONSET study, of whom 52 patients and 49 healthy controls were included in the present study. One patient and one control did not meet the inclusion criteria for the present study because they were younger than 6 years and one patient was excluded due to missing data. The study flow chart is presented in eFigure 1. Demographic and clinical data are described in Table 2. Both groups were comparable in terms of age at examination $(p=.587)$ and $\operatorname{sex}(p=.275)$. As an inherent characteristic of our subgroups, the three age-at-stroke groups differed significantly in their age at stroke $(p<.000)$ and age at examination $(p<.000)$. We did not adjust for the effect of age at examination in the following analysis, as we used age-corrected scores for all cognitive tests.

The three age-at-stroke groups were comparable in regard to sex, lesion size, and lesion laterality (Table 2). Neurological outcome (PSOM) did not differ in the three age-atstroke groups. A significant group effect was found for lesion location $(p=.016)$, revealing that cortical lesions occurred significantly more often in the neonatal group $(46.7 \%)$ compared to the late childhood stroke group (6.7\%). Across the total stroke sample, lesion size correlated negatively with intelligence $(r=-.338, p=.016)$, working memory $(r=-.335$, $p=.017)$, inhibition $(r=-.381, p=.008)$, processing speed $(r=-.319, p=.024)$, letter fluency $(r=-.444, p=.002)$, and visual-motor skills $(r=-.381, p=.050)$. Lesion location was not associated with cognitive outcome. Lesion laterality did not impact cognitive performance, except for cognitive flexibility $\left(F=4.198, p=.022, \eta_{\mathrm{p}}{ }^{2}=.167\right)$, where right hemispheric lesions entailed worse performance than left hemispheric lesions $(p=.018)$. As a consequence of these findings, all following ANCOVA analyses were adjusted for the effect of lesion size and lesion location.

\section{Long-term Cognitive Outcome in Patients and Controls}


Cognitive outcome of patients after pediatric stroke and healthy controls is displayed

in Table 3. Although mean group performance was within the normative reference range for both groups, significant lower cognitive performance occurred in all cognitive domains in patients than controls (medium to large effect-sizes). All group differences remained significant after adjusting for multiple comparisons (FDR-correction).

\section{Impact of Age at Stroke on Long-term Cognitive Outcome}

LOESS plots are displayed in Figure 1. A non-linear relationship was observed between age at stroke and cognitive outcome. Next, we investigated the impact of age at stroke on long-term cognitive outcome using a series of ANCOVAs controlling for the effect of lesion size and lesion location. Results are presented in Figure 2. A significant effect for age at stroke was found for performance in working memory $\left(F=4.131, p=.023, \eta_{\mathrm{p}}{ }^{2}=\right.$ $.155)$, cognitive flexibility $\left(F=5.368, p=.009, \eta_{\mathrm{p}}{ }^{2}=.212\right)$, processing speed $(F=6.537, p=$ $\left..003, \eta_{\mathrm{p}}{ }^{2}=.225\right)$, and verbal learning $\left(F=5.099, p=.010, \eta_{\mathrm{p}}{ }^{2}=.185\right)$ with early childhood stroke displaying the worst outcome. All effect sizes were interpreted as large. The significant effect of age at stroke on cognitive flexibility $(p=.040)$, processing speed $(p=$ .027), and verbal learning ( $p=.030)$ persisted after FDR-correction, except for working memory $(p=.052)$. Although not significant, intelligence $\left(F=2.793, p=.072, \eta_{\mathrm{p}}{ }^{2}=.110\right)$, inhibition $\left(F=1.137, p=.331, \eta_{\mathrm{p}}{ }^{2}=.051\right)$, verbal recall $\left(F=1.678, p=.199, \eta_{\mathrm{p}}{ }^{2}=.072\right)$, letter fluency $\left(F=1.748, p=.186, \eta_{\mathrm{p}}{ }^{2}=.077\right)$, and visual-motor skills $(F=3.141, p=.090$, $\eta_{\mathrm{p}}{ }^{2}=.120$ ) was slightly lower in the early childhood stroke group compared to the neonatal and late childhood stroke group. 


\section{Discussion}

In this cross-sectional study we demonstrated that patients after pediatric stroke displayed worse cognitive performance compared to a control group and that age at stroke impacts cognitive outcome. Neonatal stroke and late childhood stroke were associated with better outcome whereas early childhood stroke led to significantly worse outcome in cognitive flexibility, processing speed, and verbal learning, irrespective of lesion size and lesion location.

Our results suggest that age at stroke is an important factor for post-stroke recovery and modulates long-term cognitive outcome even when controlling for lesion size and lesion location. In contrast to previous studies indicating that younger age at stroke relates to worse ${ }^{6,10-13}$ or better cognitive outcome, ${ }^{14,15}$ our data revealed a U-shaped association between age at stroke and long-term cognitive outcome, with children after early childhood stroke showing the worst outcome. Only a limited number of studies have shown a non-linear effect of age at stroke on cognitive outcome. ${ }^{5,30,36}$ A study of 21 Swiss children after pediatric stroke found better cognitive performance in children who suffered from stroke at the age between 5 and 10 years compared to earlier $(0-5$ years $)$ or later stroke (10-18 years). ${ }^{30}$ Similarly, Allman and Scott (2013) found in a sample of 44 participants that stroke occurring between the age of 1 and 6 years entailed better cognitive outcome than earlier stroke (before the age of 1$)$ and later stroke ( 6 - 16 years). ${ }^{36}$ Both studies demonstrated an inverted Ushaped association between age at stroke and cognitive outcome which is exactly the opposite pattern compared to our data. In terms of neurological outcome, a recent study with 587 patients after pediatric stroke concluded that younger children (28 days and 1 year at the time of the stroke) are particularly vulnerable for poor neurological outcome (PSOM total score) two years after stroke when compared to children after neonatal stroke or stroke $>1$ year of age. ${ }^{5}$ This U-shaped relationship between age and outcome is in line with our results, yet, the PSOM assesses neurological (i.e. sensorimotor, language and cognitive functions) and not purely cognitive performance. 
The present study included only patients in the chronic phase of the stroke (> 2 years after stroke), whereas previous studies included patients with shorter follow-up periods as well. ${ }^{30,36}$ In fact, cognitive alterations may emerge and increase over time ${ }^{16}$ and the full extent of cognitive sequelae may only appear several years post-stroke. ${ }^{7}$ Also, developmental processes and recovery trajectories may be different depending on the cognitive function measured. ${ }^{7}$ For instance, executive functions are not fully developed until early adulthood and rely on intact frontal and prefrontal cortices. ${ }^{37}$ This highlights the importance of longterm follow ups in patients after pediatric stroke in order to identify patients particularly at risk for alterations in long-term cognitive outcome. ${ }^{7}$

There is an ongoing debate around plasticity and vulnerability of the developing brain following early brain injury. ${ }^{7-9}$ The early plasticity approach supports the idea of maximum plasticity in the developing brain with better recovery of cognitive functions after brain lesion in childhood compared to adulthood. ${ }^{7,8}$ In contrast, the vulnerability perspective argues that the developing brain is particularly vulnerable to stroke which leads to disrupted brain and cognitive development. ${ }^{7,30,38}$ Our results did not favor one or the other perspective but supports a recent idea combining these to concepts to a "recovery continuum", suggesting that cognitive outcome after stroke is determined by several factors such as age at stroke, lesion-related characteristics, and sociodemographic factors. ${ }^{7}$ Hence, our results may be inconsistent with previous studies, ${ }^{30,36}$ because several factors affect cognitive outcome and, for instance, patient or lesion characteristics vary across studies.

Findings from the present study propose that early childhood is a particularly vulnerable developmental period in terms of post-stroke cognitive outcome. Between the age of 29 days to < 6 years, cognitive functions measured in our study are about to emerge and continuously develop, however, none of the cognitive domains we have measured is fully established yet. Hence, in line with previous findings from epilepsy research, we suggest that stroke during a critical period of cognitive development has a particularly detrimental effect on outcome. ${ }^{18,19}$ This is further supported by neuroimaging studies, revealing that functional 
and structural brain development is a non-linear process with critical periods for plasticity as well as maturational processes (i.e. myelination and synaptogenesis). ${ }^{39-41}$

In addition, we examined our total stroke sample with regard to the effect of lesion size, lesion location, and lesion laterality on cognitive outcome. Larger lesion size was related to poorer performance in intelligence, working memory, inhibition, processing speed, letter fluency, and visual-motor skills in the present study, which is consistent to previous findings. ${ }^{30,42}$ Also in line with previous findings, ${ }^{11}$ we found that cortical lesions occurred more often in the neonatal group compared to the late childhood stroke group. In terms of the effect of lesion location on cognitive outcome, previous findings are inconsistent. Whereas Westmacott et al. (2010) suggest that combined lesions (cortical and subcortical) were associated with worse cognitive performance, other studies ${ }^{12,30}$ as well as our data did not reveal an impact of lesion location on cognitive outcome. However, different approaches to classify lesion location hinders comparability between studies. Further, except for cognitive flexibility, lesion laterality did not impact cognitive performance. Our data support the functional network approach, claiming that even remote lesion locations can affect functional brain networks and thus impact on cognitive performance. ${ }^{43}$

A strength of our study is the large sample size of 52 patients after pediatric stroke, a rare neurological disease in childhood (incidence of neonatal ischemic stroke in Switzerland 13 per 100'000 live births, ${ }^{44}$ incidence of childhood stroke in Switzerland 2.1:100'000 children per year $\left.{ }^{23}\right)$. The inclusion of a control group further strengthens our study. We only included patients in the chronic phase of the stroke ( $>2$ years after stroke) allowing us to draw conclusions about long-term cognitive outcome. Other strengths include the broad spectrum of cognitive functions assessed in this study. Further, we estimated lesion size using a relatively new method in pediatrics and pediatric neuroimaging, namely the pedASPECTS, which has fair to good accuracy for predicting cerebral palsy as well as neurologic impairment and was shown to correlate with infarct volume. ${ }^{28}$ Additionally, the present findings remain robust after adjusting for multiple testing (FDR-correction). 
Some limitations have to be acknowledged. First, the cross-sectional design of this study does not allow to draw conclusions about developmental trajectories of cognitive functions. Second, our age-at-stroke groups were defined according to a prior study. ${ }^{11}$ Other studies adopted different classification approaches. ${ }^{6,30,36}$ However, when defining the cut-offs differently, the effect of our results remained similar. Third, pediatric stroke is a heterogeneous disease with diverse clinical presentation and etiology, hindering comparability across studies. Fourth, for a small number of patients, acute neuroimaging was not available. Determining pedASPECTS on post-acute imaging may have led to underestimation of the score since punctate lesions may become unrecognizable due to so called "pseudonormalization" of diffusion restriction, or - in the chronic stage - may shrink over time and remain hardly visible. Yet, pedASPECTS of patients with post-stroke MRI did not differ from pedASPECTS determined on the acute MRI. Fifth, the present patient group may be biased as it does not account for patients who were lost to follow up or have died during the post-stroke phase. Likewise, a large number of potential participants were too young $(n=112)$ or unwilling to participate in the present study $(n=191)$, increasing the risk of a potential selection bias.

To conclude, we have shown that long-term cognitive outcome varied according to age at stroke in a population of pediatric stroke survivors without severe learning difficulties. Our findings suggest a non-linear relationship between age at stroke and cognitive outcome with patients after early childhood stroke ( 29 days to $<6$ years) performing worse than patients after neonatal or late childhood stroke. These results propose that early childhood is a particular vulnerable developmental period for negative long-term cognitive outcome in survivors of pediatric stroke, irrespective of lesion size and lesion location. Children following early childhood stroke should be monitored closely and provided with adequate treatment and rehabilitation options tailored on their age at stroke and current developmental period in order to prevent cognitive sequelae and improve cognitive outcome. 


\section{Supplement -- http://links.lww.com/WNL/B701}

\section{References}

1. Steinlin M. A clinical approach to arterial ischemic childhood stroke: Increasing knowledge over the last decade. Neuropediatrics. 2012;43(1):1-9. doi:10.1055/s-00321307449

2. Jordan LC, Hillis AE. Challenges in the diagnosis and treatment of pediatric stroke. Nat Rev Neurol. 2011;7(4):199-208. doi:10.1038/nrneurol.2011.23

3. Kornfeld S, Delgado Rodríguez JA, Everts R, et al. Cortical reorganisation of cerebral networks after childhood stroke: impact on outcome. BMC Neurol. 2015;15(1):90. doi:10.1186/s12883-015-0309-1

4. Jiang B, Hills NK, Forsyth R, et al. Imaging Predictors of Neurologic Outcome after Pediatric Arterial Ischemic Stroke. Stroke. 2020;(January):152-161. doi:10.1161/STROKEAHA.120.030965

5. Felling RJ, Rafay MF, Bernard TJ, et al. Predicting Recovery and Outcome after Pediatric Stroke: Results from the International Pediatric Stroke Study. Ann Neurol. 2020;87(6):840-852. doi:10.1002/ana.25718

6. Studer M, Boltshauser E, Capone Mori A, et al. Factors affecting cognitive outcome in early pediatric stroke. Neurology. 2014;82:784-792.

7. Anderson V, Spencer-Smith M, Wood A. Do children really recover better? Neurobehavioural plasticity after early brain insult. Brain. 2011;134:2197-2221. doi:10.1093/brain/awr103

8. Ballantyne AO, Spilkin AM, Hesselink J, Trauner DA. Plasticity in the developing brain: Intellectual, language and academic functions in children with ischaemic perinatal stroke. Brain. 2008;131(11):2975-2985. doi:10.1093/brain/awn176

9. Johnston M V. Plasticity in the developing brain: implications for rehabilitation. Dev Disabil Res Rev. 2009;15(2):94-101. doi:10.1002/ddrr.64

10. Jacomb I, Porter M, Brunsdon R, Mandalis A, Parry L. Cognitive outcomes of pediatric stroke. Child Neuropsychol. 2018;24(3):287-303. doi:10.1080/09297049.2016.1265102

11. Westmacott R, Askalan R, Macgregor D, Anderson P, Deveber G. Cognitive outcome following unilateral arterial ischaemic stroke in childhood: effects of age at stroke and lesion location. Dev Med Child Neurol. 2010;52(4):386-393. doi:10.1111/j.14698749.2009.03403.x

12. Pavlovic J, Kaufmann F, Boltshauser E, et al. Neuropsychological Problems after Paediatric Stroke: Two Year Follow-Up of Swiss Children. Neuropediatrics. 2006;37:13-19. doi:10.1055/s-2006-923932

13. Lansing AE, Max JE, Delis DC, et al. Verbal learning and memory after childhood stroke. J Int Neuropsychol Soc. 2004;10(5):742-752. doi:10.1017/S1355617704105122

14. O'Keeffe F, Liégeois F, Eve M, Ganesan V, King J, Murphy T. Neuropsychological and neurobehavioral outcome following childhood arterial ischemic stroke: Attention deficits, emotional dysregulation, and executive dysfunction. Child Neuropsychol. 2014;20(5):557-582. doi:10.1080/09297049.2013.832740

15. DeVeber GA, MacGregor D, Curtis R, Mayank S. Neurologic Outcome in Survivors of Childhood Arterial Ischemic Stroke and Sinovenous Thrombosis. J Child Neurol. 2000;15(5):316-324. doi:10.1177/088307380001500508

16. Westmacott R, Macgregor D, Askalan R, Deveber G. Late emergence of cognitive deficits after unilateral neonatal stroke. Stroke. 2009;40(6):2012-2019. doi:10.1161/STROKEAHA.108.533976

17. Ballester BR, Maier M, Duff A, et al. A critical time window for recovery extends 
beyond one-year post-stroke. J Neurophysiol. 2019;122(1):350-357.

doi:10.1152/jn.00762.2018

18. Fox SE, Levitt P, Nelson CA. How the Timing and Quality of Early Experiences Influence the Development of Brain Architecture. Child Dev. 2010;81(1):28-40. doi:10.1111/j.1467-8624.2009.01380.x

19. Gonzalez LM, Embuldeniya US, Harvey AS, et al. Developmental stage affects cognition in children with recently-diagnosed symptomatic focal epilepsy. Epilepsy Behav. 2014;39:97-104. doi:10.1016/j.yebeh.2014.08.006

20. Laporta-Hoyos O, Ballester-Plané J, Póo P, et al. Proxy-reported quality of life in adolescents and adults with dyskinetic cerebral palsy is associated with executive functions and cortical thickness. Qual Life Res. 2017;26(5):1209-1222. doi:10.1007/s11136-016-1433-0

21. St Clair-Thompson HL, Gathercole SE. Executive functions and achievements in school: Shifting, updating, inhibition, and working memory. $Q J$ Exp Psychol. 2006;59(4):745-759. doi:10.1080/17470210500162854

22. Semrud-Clikeman M. Social Competence in Children. New York, NY: Springer; 2007.

23. Steinlin M, Pfister I, Pavlovic J, et al. The First Three Years of the Swiss Neuropaediatric Stroke Registry (SNPSR): A Population-Based Study of Incidence, Symptoms and Risk Factors. Neuropediatrics. 2005;36(2):90-97. doi:10.1055/s-2005837658

24. Steinlin M, Wehrli E. Der kindliche ischämische Schlaganfall. Wann daran denken was unternehmen? Paediatrica. 2009;20(2):17-21.

25. Beslow LA, Vossough A, Dahmoush HM, et al. Modified pediatric ASPECTS correlates with infarct volume in childhood arterial ischemic stroke. 2012;i(July):1-7. doi:10.3389/fneur.2012.00122

26. Barber PA, Demchuk AM, Zhang J, Buchan AM, Study A. Validity and reliability of a quantitative computed tomography score in predicting outcome of hyperacute stroke before thrombolytic therapy. 2000;355:1670-1674.

27. Schröder J, Thomalla G. A Critical Review of Alberta Stroke Program Early CT Score for Evaluation of Acute Stroke Imaging. Front Neurol. 2017;7. doi:10.3389/fneur.2016.00245

28. Mackay MT, Slavova N, Pastore-Wapp M, et al. Pediatric ASPECTS predicts outcomes following acute symptomatic neonatal arterial stroke. Neurology. 2020;94(12):e1259-e1270. doi:10.1212/WNL.0000000000009136

29. Slavova N, Fullerton HJ, Hills NK, Breiding PS, Mackay MT, Steinlin M. Validation of the focal cerebral arteriopathy severity score (FCASS) in a Swiss cohort: Correlation with infarct volume and outcome. Eur J Paediatr Neurol. 2020;28:58-63. doi:10.1016/j.ejpn.2020.07.015

30. Everts R, Pavlovic J, Kaufmann F, et al. Cognitive Functioning, Behavior, and Quality of Life After Stroke in Childhood. Child Neuropsychol. 2008;14(4):323-338. doi:10.1080/09297040701792383

31. Kitchen L, Westmacott R, Friefeld S, et al. The Pediatric Stroke Outcome Measure A Validation and Reliability Study. Stroke. 2012;43(6):1602-1608. doi:10.1161/STROKEAHA.111.639583

32. Cleveland WS, Devlin SJ. Locally weighted regression: An approach to regression analysis by local fitting. J Am Stat Assoc. 1988;83(403):596-610. doi:10.1080/01621459.1988.10478639

33. Cohen J. Statistical Power Analysis for the Behavioral Sciences.; 1988.

34. Benjamini Y, Hochberg Y. Controlling the False Discovery Rate: A Practical and Powerful Approach to Multiple Testing. J R Stat Soc. 1995;57(1):289-300.

35. Wickham H. Ggplot2 Elegant Graphics for Data Analysis. New York (NY): Springer; 
2016. http://had.co.nz/ggplot2/book.

36. Allman C, Scott RB. Neuropsychological sequelae following pediatric stroke : A nonlinear model of age at lesion effects. Child Neuropsychol. 2013;19(1):97-107.

37. Anderson V. Assessing executive functions in children : biological, psychological, and developmental considerations. Pediatr Rehabil. 2001;4(3):119-136.

38. Cnossen MH, Aarsen FK, Lj S, Renee VANDENA. Paediatric arterial ischaemic stroke : functional outcome and risk factors. 2010. doi:10.1111/j.14698749.2009.03580.x

39. Gogtay N, Giedd JN, Lusk L, et al. Dynamic mapping of human cortical development during childhood through early adulthood. Proc Natl Acad Sci U S A. 2004;101(21):8174-8179. doi:10.1073/pnas.0402680101

40. Andersen SL. Trajectories of brain development: Point of vulnerability or window of opportunity? Neurosci Biobehav Rev. 2003;27(1-2):3-18. doi:10.1016/S01497634(03)00005-8

41. Forbes TA, Gallo V. All Wrapped Up: Environmental Effects on Myelination. Trends Neurosci. 2017;40(9):572-587. doi:10.1016/j.tins.2017.06.009

42. Hajek CA, Yeates KO, Anderson V, et al. Cognitive Outcomes Following Arterial Ischemic Stroke in Infants and Children. J Child Neurol. 2014;29(7):887-894. doi:10.1177/0883073813491828

43. Long B, Spencer-Smith MM, Jacobs R, et al. Executive Function Following Child Stroke: The Impact of Lesion Location. J Child Neurol. 2011;26(3):279-287. doi:10.1177/0883073810380049

44. Grunt S, Mazenauer L, Buerki SE, et al. Incidence and Outcomes of Symptomatic Neonatal Arterial Ischemic Stroke. Pediatrics. 2015;135(5):e1220-e1228.

45. Brown L, Sherbenou RJ, Johnsen SK. TONI-4: Test of Nonverbal Intelligence-Fourth Edition. Austin, TX.: Pro-ed; 2010.

46. Petermann F, Petermann UJ. Wechsler Intelligence Scale for Children ${ }^{\circledR}$ - Fourth Edition. 2012;(September 2011).

47. Petermann F. Wechsler Adult Intelligence Scale - Fourth Edition. Frankfurt, Germany: Pearson; 2012.

48. Delis DC, Kaplan E, Kramer J. Delis Kaplan Executive Function System (D-KEFS). San Antonio, TX: Pearson Psychological Corporation; 2001.

49. Helmstaedter C, Lendt M, Lux S. Verbaler Lern- Und Merkfähigkeitstest (VLMT). Göttingen, Germany: Beltz; 2001.

50. Beery KE, Beery NA, Buktenica NA. Beery-Buktenica Developmental Test of VisualMotor Integration. 6th editio. San Antonio, TX; 2010. 
Figure 1. Association between age at stroke and long-term cognitive outcome

LOESS plots of cognitive outcome as a function of age at stroke. X-axis represents age at stroke (in years). 95\% confidence interval in grey. IS = Index score; SS = Standard score; PR $=$ Percentile range.
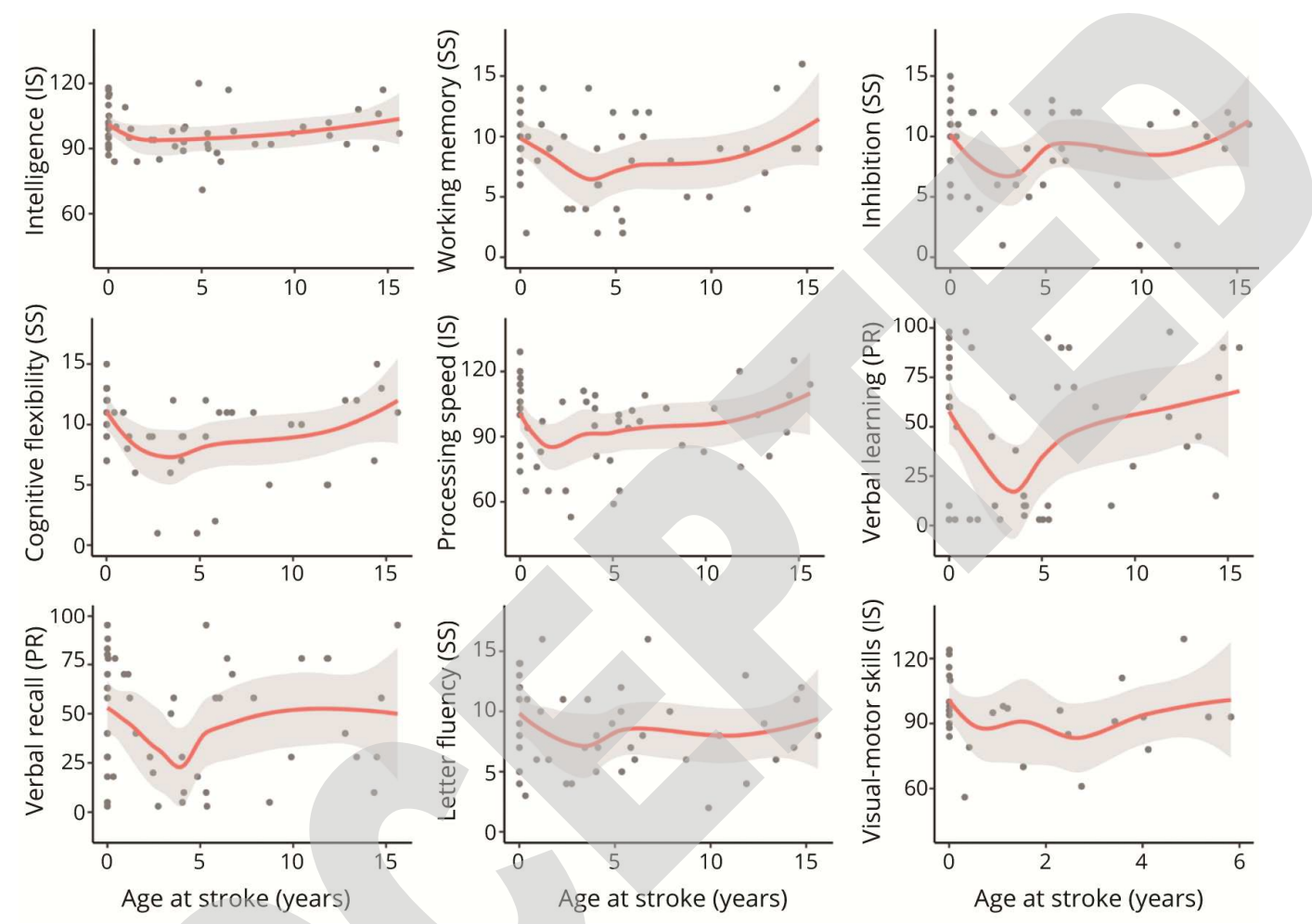
Figure 2. Impact of age at stroke on long-term cognitive outcome

learning was found ( $<<.05$, FDR-corrected). Estimated marginal means (adjusted for the mean of covariates) with associated $95 \%$ confidence interval are displayed on the $\mathrm{x}$-axis for the three age-at-stroke groups: neonatal stroke (red), early childhood (green), and late childhood (blue). Due to missing normative data, data about visual-motor skills was not available for the late childhood stroke group. IS = Index score; SS = Standard score; PR = percentile range. Significant Bonferroni post hoc results are marked with *.*p<.05,**p< .01 .
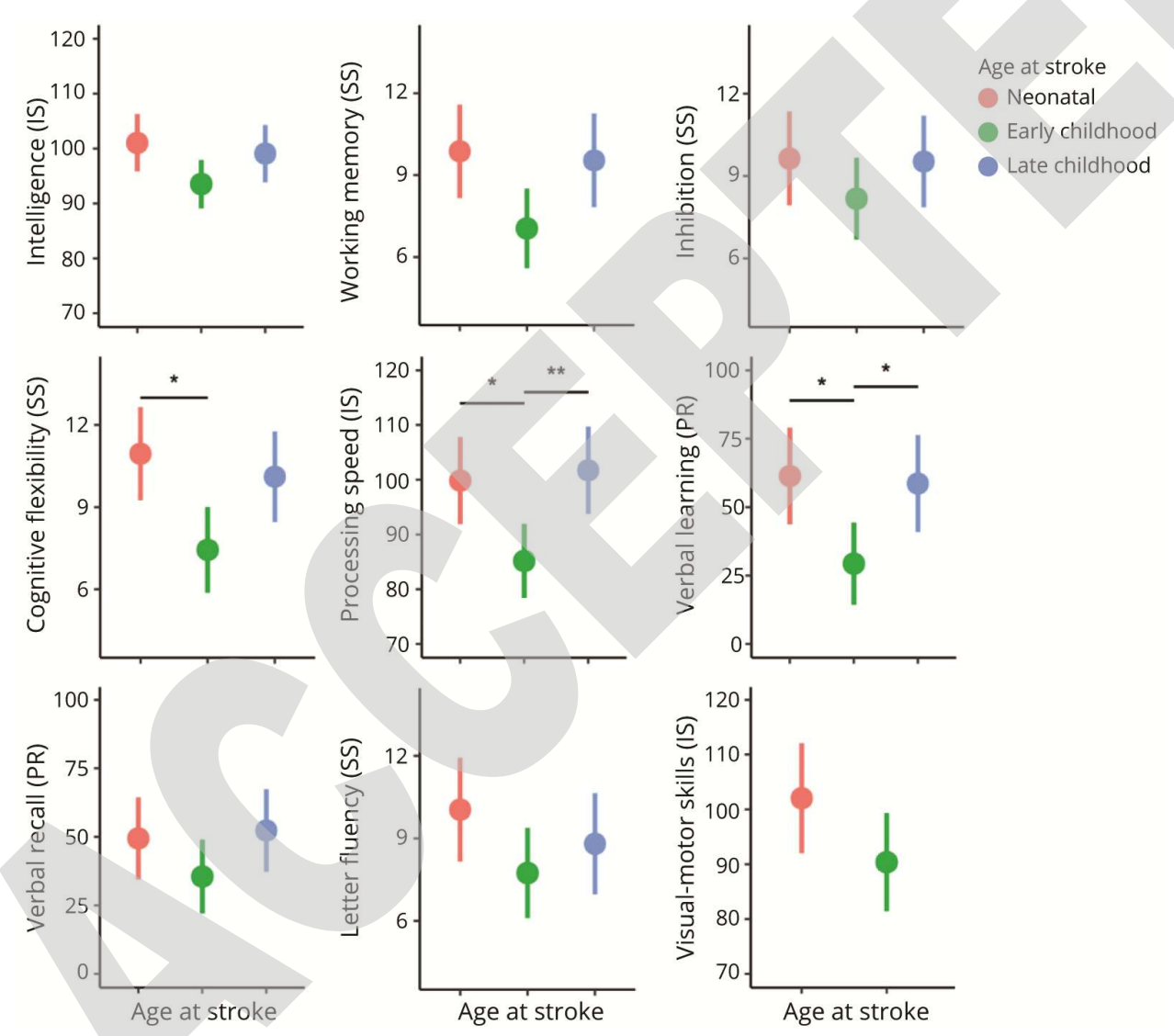


\section{IMPACT OF AGE AT STROKE ON COGNITIVE OUTCOME}

Table 1. Overview of the cognitive assessment

\begin{tabular}{|c|c|c|c|c|c|}
\hline Cognitive Domain & Test & Task description & Outcome measure & Scores & Missing data \\
\hline Intelligence & $\mathrm{TONI}^{45}$ & Pattern completion task & Number of correct answers & IS & \\
\hline \multicolumn{6}{|l|}{ Executive functions } \\
\hline Working memory & $\begin{array}{l}\text { Letter-number } \\
\text { Sequencing } \\
46,47\end{array}$ & $\begin{array}{l}\text { Repetition of an auditory presented sequence of } \\
\text { numbers and letters }\end{array}$ & $\begin{array}{l}\text { Number of correct } \\
\text { sequences }\end{array}$ & SS & \\
\hline Inhibition & $\mathrm{CWI}^{48}$ & $\begin{array}{l}\text { Naming the color of color words, printed in } \\
\text { incongruent color ink }\end{array}$ & Completion time & SS & $\begin{array}{l}\mathrm{C}: n=7^{\mathrm{a}} \\
\mathrm{P}: n=3\end{array}$ \\
\hline Cognitive flexibility & $\mathrm{TMT}^{48}$ & $\begin{array}{l}\text { Connecting numbers and letters in alternating } \\
\text { order }\end{array}$ & Completion time & SS & $\begin{array}{l}\mathrm{C}: n=6^{\mathrm{a}} \\
\mathrm{P}: n=5\end{array}$ \\
\hline Processing Speed & $\begin{array}{l}\text { Coding and Symbol } \\
\text { search }^{46,47}\end{array}$ & $\begin{array}{l}\text { Coding: Matching numbers to symbols using a } \\
\text { number-symbol key } \\
\text { Symbol search: Finding a target symbol in a } \\
\text { group of symbols }\end{array}$ & Number of correct answers & IS & \\
\hline \multicolumn{6}{|l|}{ Memory } \\
\hline Verbal learning & 49 & $\begin{array}{l}\text { Immediate recall of } 15 \text { item word list after } \\
\text { auditory presentation ( } \sum \text { DG1-5) }\end{array}$ & $\begin{array}{l}\text { Sum of correct answers in } 5 \\
\text { trials }\end{array}$ & PR & \\
\hline Verbal recall & VLMT & $\begin{array}{l}\text { Delayed recall (30 min) of the } 15 \text { item word list } \\
\text { (DG 7) }\end{array}$ & $\begin{array}{l}\text { Number of correct retrieved } \\
\text { words }\end{array}$ & PR & $\mathrm{P}: n=2$ \\
\hline Letter Fluency & Verbal fluency $^{48}$ & $\begin{array}{l}\text { Generating as many words beginning with a } \\
\text { specific letter within } 60 \mathrm{sec}\end{array}$ & Number of correct answers & SS & $\begin{array}{l}\mathrm{C}: n=6^{\mathrm{a}} \\
\mathrm{P}: n=3\end{array}$ \\
\hline Visual-motor skills & Visual-motor integration $^{50}$ & Copying geometric designs & $\begin{array}{l}\text { Number of correct imitated } \\
\text { designs }\end{array}$ & IS & $\begin{array}{l}\mathrm{C}: n=17^{\mathrm{b}} \\
\mathrm{P}: n=9\end{array}$ \\
\hline
\end{tabular}

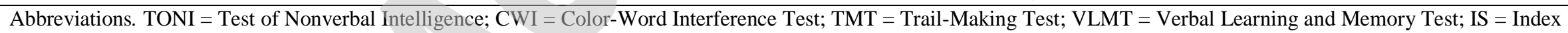
score $($ mean $=100, \mathrm{SD}=15) ; \mathrm{SS}=$ Standard score $($ mean $=10, \mathrm{SD}=3) ; \mathrm{PR}=$ Percentile rank $($ mean $=50, \mathrm{SD}=34.1) ; \mathrm{C}=\mathrm{Controls} ; \mathrm{P}=\mathrm{Patients}$

${ }^{a}$ According to the manual, normative data is only available from the age of 8 years.

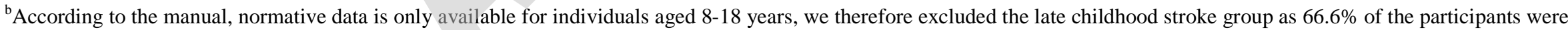
older than 18 years at the time of the assessment and normative data was not available. 
Table 2. Demographic and clinical data for the total stroke sample, the three age-at-stroke groups, and the control sample

\begin{tabular}{|c|c|c|c|c|c|c|c|}
\hline & \multirow[t]{2}{*}{ Total stroke } & \multicolumn{3}{|c|}{ Age-at-stroke groups } & \multirow[t]{2}{*}{ Controls } & \multirow[t]{2}{*}{$U / \chi 2^{a}$} & \multirow[t]{2}{*}{$F / \chi 2^{b}$} \\
\hline & & $\begin{array}{l}\text { Neonatal stroke } \\
(0-28 \mathrm{~d})\end{array}$ & $\begin{array}{l}\text { Early childhood } \\
\text { Stroke }(29 \text { d to }<6 \text { y) }\end{array}$ & $\begin{array}{l}\text { Late childhood stroke } \\
(\geq 6 \text { to }<16 \text { y) }\end{array}$ & & & \\
\hline Sample size & 52 & 16 & 21 & 15 & 49 & - & - \\
\hline Male & $29(55.8)$ & $8(50.0)$ & $13(61.9)$ & $8(53.3)$ & $22(44.9)$ & 1.193 & .572 \\
\hline Age at examination & $15.3(10.6-18.7)$ & $12.5(9.3-16.5)$ & $13.2(10.3-16.2)$ & $18.8(15.5-22.3)$ & $13.6(9.8-17.2)$ & 1185.00 & $11.14 * * *$ \\
\hline Age at stroke & $3.5(0.0-6.7)$ & $2.0(1.0-2.8)^{1}$ & $3.6(1.4-4.9)$ & $11.8(7.9-14.4)$ & - & - & $104.67 * * * 1$ \\
\hline PSOM total & $.5(.0-1.0)$ & $.3(.0-1.0)$ & $.3(.0-.9)$ & $.5(.0-1.0)$ & - & - & $.058^{2}$ \\
\hline pedASPECTS & $4(2-6.5)$ & $3(2-8)^{3}$ & $4(3-5)^{3}$ & $4(1-8)$ & - & - & $.801^{2}$ \\
\hline \multicolumn{8}{|l|}{ Lesion laterality } \\
\hline Left & $27(54.0)$ & $11(73.3)$ & $8(40.0)$ & $8(53.3)$ & \multirow{3}{*}{-} & \multirow{3}{*}{-} & \multirow{3}{*}{$5.652^{5}$} \\
\hline Right & $15(30.0)$ & $3(20.0)$ & $9(45.0)$ & $3(20.0)$ & & & \\
\hline Bilateral & $8(16.0)$ & $1(6.7)$ & $3(15.0)$ & $4(26.7)$ & & & \\
\hline \multicolumn{8}{|l|}{ Lesion location } \\
\hline Subcortical & $8(16.0)$ & 0 & $3(15.0)$ & $5(33.3)$ & \multirow{3}{*}{ - } & \multirow{3}{*}{-} & \multirow{3}{*}{$9.520 *^{5}$} \\
\hline Cortical & $14(28.0)$ & $7(46.7)$ & $6(30.0)$ & $1(6.7)$ & & & \\
\hline Both & $28(56.0)$ & $8(53.3)$ & $11(55.0)$ & $9(60.0)$ & & & \\
\hline \multicolumn{8}{|l|}{ Stroke risk factors } \\
\hline Infections & $9(17.3)$ & $1(6.2)$ & $5(23.8)$ & $3(20.0)$ & & & \\
\hline Vasculopathy & $2(3.8)$ & 0 & 0 & $2(13.3)$ & & & \\
\hline Cardiac disorders & $7(13.5)$ & $3(18.8)$ & $4(19.0)$ & 0 & & \multirow{4}{*}{-} & \multirow{4}{*}{-} \\
\hline Haematological disorders & $3(5.8)$ & $1(6.2)$ & $1(4.8)$ & $1(6.7)$ & & & \\
\hline Multiple risk factors & $13(25.0)$ & 0 & $8(38.1)$ & $5(33.3)$ & & & \\
\hline No identifiable risk factor & $18(34.6)$ & $11(68.8)$ & $3(14.3)$ & $4(26.7)$ & & & \\
\hline
\end{tabular}


Abbreviations: $U=$ Mann-Whitney U test (two-sided); $\chi 2=$ Pearson's chi-square; $F=$ Analysis of Variance (ANOVA); PSOM = Pediatric Stroke Outcome Measure; $* p<.05, * * p<.01, * * * p<.001$

Data are presented in frequencies $(\%)$ for categorical variables or median (interquartile range) for continuous variables.

${ }^{a}$ Comparisons between the total stroke group and the control group

${ }^{\mathrm{b}}$ Comparisons within the three age-at-stroke groups

1 in days.

${ }^{2}$ Kruskal-Wallis test was performed as data was non-normally distributed.

${ }^{3}$ Missing data for one participant.

${ }^{4}$ Mann-Whitney $U$ test was performed as data was non-normally distributed.

${ }^{5}$ Fisher's exact test was performed. 
Table 3. Mean cognitive performance for the total stroke sample, the three age-at-stroke groups, and the control sample

\begin{tabular}{|c|c|c|c|c|c|c|c|}
\hline \multirow[t]{2}{*}{ Cognitive outcome } & \multirow[t]{2}{*}{ Total Stroke } & \multicolumn{3}{|c|}{ Age-at-stroke groups } & \multirow[t]{2}{*}{ Controls } & \multirow[t]{2}{*}{$t^{\mathrm{a}}$} & \multirow[t]{2}{*}{$d$} \\
\hline & & $\begin{array}{l}\text { Neonatal stroke } \\
(0 \text { to } 28 \mathrm{~d})\end{array}$ & $\begin{array}{l}\text { Early childhood } \\
\text { stroke }(29 \text { d to }<6 \text { y) }\end{array}$ & $\begin{array}{l}\text { Late childhood stroke } \\
(\geq 6 \text { to }<16 \text { y) }\end{array}$ & & & \\
\hline Intelligence & $97.8(10.3)$ & $101.4(10.5)$ & $93.9(9.9)$ & $99.2(9.5)$ & $103.7(9.8)$ & $2.976 * *$ & .59 \\
\hline \multicolumn{8}{|l|}{ Executive functions } \\
\hline Working memory & $8.7(3.5)$ & $10.1(2.4)$ & $7.2(3.9)$ & $9.2(3.3)$ & $10.5(2.1)$ & $3.109 * *$ & .62 \\
\hline Inhibition & $9.1(3.4)$ & $10.0(3.1)$ & $8.4(3.4)$ & $9.1(3.7)$ & $11.0(2.2)$ & $3.188 * *$ & .66 \\
\hline Cognitive flexibility & $9.5(3.3)$ & $11.0(2.3)$ & $7.7(3.5)$ & $9.9(3.1)$ & $11.0(2.5)$ & $2.445^{*}$ & .51 \\
\hline Processing speed & $95.2(17.6)$ & $102.9(14.2)$ & $85.9(18.2)$ & $100.0(14.4)$ & $109.0(13.6)$ & $4.394 * * *$ & .88 \\
\hline \multicolumn{8}{|l|}{ Memory } \\
\hline Verbal learning & $48.0(35.6)$ & $58.9(34.9)$ & $30.1(34.3)$ & $61.5(28.6)$ & $64.8(29.40)$ & $2.589 *$ & .51 \\
\hline Verbal recall & $46.8(29.2)$ & $51.8(30.3)$ & $37.9(28.6)$ & $52.7(27.8)$ & $60.9(27.5)$ & $2.486^{*}$ & .50 \\
\hline Letter fluency & $8.9(3.8)$ & $10.6(4.20)$ & $8.0(3.4)$ & $8.4(3.6)$ & $11.9(3.7)$ & $3.375^{* * *}$ & .78 \\
\hline Visual-motor skills & $95.0(17.4)$ & $102.8(13.6)$ & $89.1(18.0)$ & - & $108.5(11.2)$ & $3.632 * *$ & .93 \\
\hline
\end{tabular}

Abbreviations. $t=$ two sample $t$-test (two-sided); $d=$ Cohen's $d$ effect size, with $d=.2$ small effect, $d=.5$ medium effect, and $d=.8$ large effect; * $p<.05, * * p<.01$, $* * * p<.001$.

Data are presented in mean (SD).

${ }^{\mathrm{a} C}$ Comparisons between the total stroke group and the control group 


\section{Neurology}

\section{Impact of Age at Pediatric Stroke on Long-term Cognitive Outcome}

Stephanie Abgottspon, Qendresa Thaqi, Leonie Steiner, et al.

Neurology published online December 16, 2021

DOI 10.1212/WNL.0000000000013207

This information is current as of December 16, 2021

\section{Updated Information \& Services}

Citations

Subspecialty Collections

Permissions \& Licensing

Reprints including high resolution figures, can be found at: http://n.neurology.org/content/early/2021/12/16/WNL.0000000000013207.f ull

This article has been cited by 1 HighWire-hosted articles: http://n.neurology.org/content/early/2021/12/16/WNL.0000000000013207.f ull\#\#otherarticles

This article, along with others on similar topics, appears in the following collection(s):

Childhood stroke

http://n.neurology.org/cgi/collection/childhood_stroke

Executive function

http://n.neurology.org/cgi/collection/executive_function

Intelligence

http://n.neurology.org/cgi/collection/intelligence

Neuropsychological assessment

http://n.neurology.org/cgi/collection/neuropsychological_assessment Pediatric stroke; see Cerebrovascular Disease/ Childhood stroke http://n.neurology.org/cgi/collection/pediatric_stroke_see_cerebrovascular_ disease-childhood_stroke

Information about reproducing this article in parts (figures,tables) or in its entirety can be found online at:

http://www.neurology.org/about/about_the_journal\#permissions

Information about ordering reprints can be found online:

http://n.neurology.org/subscribers/advertise

Neurology ${ }^{\circledR}$ is the official journal of the American Academy of Neurology. Published continuously since 1951, it is now a weekly with 48 issues per year. Copyright Copyright (C) 2021 The Author(s). Published by Wolters

Kluwer Health, Inc. on behalf of the American Academy of Neurology.. All rights reserved. Print ISSN:

0028-3878. Online ISSN: 1526-632X.

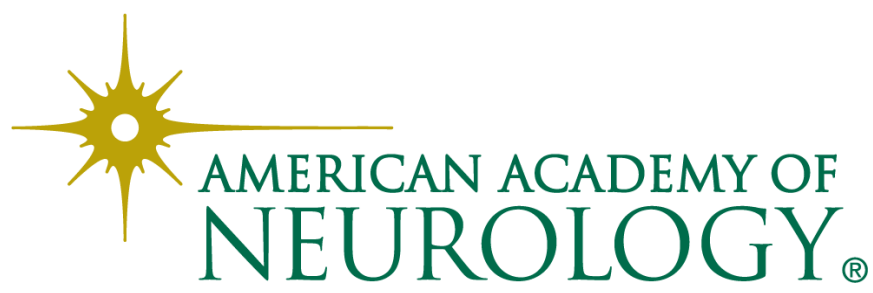

